\title{
Life Histories and Conservation Needs of Bats of the U.S. and Canada
}

\author{
BATS OF THE UNITED STATES AND CANADA. Edited by Michael J. Harvey, J. Scott \\ Altenbach, and Troy L. Best. Baltimore: The Johns Hopkins University Press. 2011. 202 \\ pp., \$24.95 (paperback). ISBN 1-4214-0191-6.
}

\author{
Michael D. Baker \\ Published online: 5 June 2012 \\ (C) Springer Science+Business Media, LLC 2012
}

The study of bats in North America has benefitted from intersecting networks of talented and productive scientists and graduate students in this region for many decades. A remarkable collegiality among these networks is on display at the annual 'bat meetings' conducted by the North American Society for Bat Research, the Western Bat Working Group, the Southeastern Bat Diversity Network, the Northeastern Bat Working Group, and the Midwestern Bat Working Group. The conservation of bats in North America has benefitted from the collegiality and mutual respect among members of these organizations, including scientists working in academia, government agencies, and non-profit conservation organizations. The authors of this new text, Bats of the United States and Canada, are highly-respected and long-term members of this 'bat community' who have each contributed greatly to knowledge of bats both through their own research and through that of the many students they have mentored. This book acknowledges contributions from the larger bat research community up front, rather than attempting to provide references for each detail; a comprehensive index is provided. The stated goal of the authors, to provide an accurate and concise representation of the life history and conservation status of Nearctic bat species, is realized with this book; and, as emphasized in the forward, this information results ultimately from the aforementioned decades of collegiality present within the North American bat community.

This book was likely conceived to focus on bats that occur in the United States; however, because all 20 of the bat species that occur in Canada also occur in the United

\footnotetext{
M. D. Baker $(\bowtie)$

Bat Conservation and Research,

Versailles, KY 40383, USA

e-mail: mdbaker6@gmail.com
}

States - and because a large percentage of the North American 'bat community' of scientists whose high-quality work contributed to this compendium of current knowledge are Canadian-Canada had to be included in the book's title. Perhaps because there are 137 species of bats in Mexico, this book focuses on the 47 North American species that occur north of Mexico, in the United States and Canada, although it includes accounts for four additional species of 'accidental' occurrence in the region covered. Given historical persecution of bats resulting from ignorance and habitat destruction resulting from human 'land development,' coupled with the relatively recently realized, and greatest threat to New World bats, the disease, known as White-nose Syndrome (i.e., a dermal infection by a newly-named and recently-introduced soil fungus, Geomyces destructans), which affects bats that utilize caves and mines in the region covered by this book, the volume is a timely and important contribution to bat literature.

Roughly half of this book provides up-to-date information on three dozen bat-related subject areas. Highlights include: academic aspects of bats' taxonomy, biology, and ecology; anthropogenic considerations like myths, threats, control, conservation, and protection status; and standard and emerging research techniques. The other half of the book consists of one-page summaries of each species' life history, including description, distribution, habitat, habits, and diet, reproduction, and conservation status when known, with nearly life-size color photographs and range maps. While no field worker will encounter more than onethird of the included species in any one region of the U.S. or Canada, the physical size and quality up-to-date information presented within this book combine to make it a useful field reference. Moreover, it is a nice addition to home and library bookshelves everywhere. 